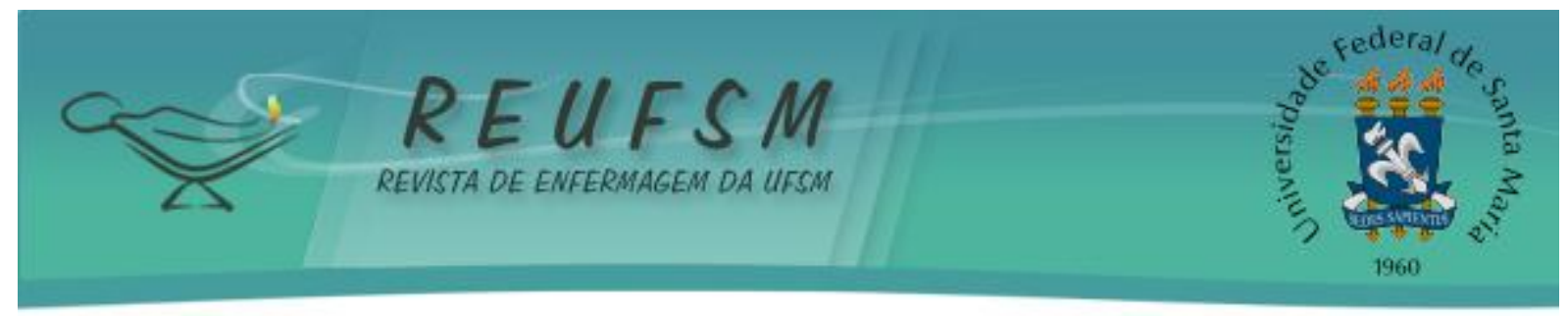

ARTIGO DE REVISÃO

\title{
ALEITAMENTO MATERNO NA PREMATURIDADE: UMA REVISÃO INTEGRATIVA
}

\author{
BREAST FEEDING IN PREMATURE INFANTS: AN INTEGRATIVE REVIEW
}

LA LACTANCIA MATERNA EN PREMATUROS: UNA REVISIÓN INTEGRADORA

\author{
Eveline Franco da Silva ${ }^{1}$ \\ Fernanda Muniz ${ }^{2}$ \\ Fátima Helena Cecchetto ${ }^{3}$
}

RESUMO: Objetivo: analisar as produções científicas relacionadas ao aleitamento materno na prematuridade. Método: trata-se de uma revisão integrativa desenvolvida através do Scientific Electronic Library Online. Foram incluídos 12 artigos, oriundos de estudos realizados no Brasil, publicados no período de 2000 e 2009. Resultados: os estudos abordaram a importância do aleitamento materno na prematuridade, as influências positivas e negativas para esta prática e atuação dos profissionais neste contexto. A maior incidência de publicações ocorreu no ano de 2004. Quanto à autoria, evidenciou-se maior empreendimento dos enfermeiros sobre os demais profissionais. Considerações finais: os estudos analisados apresentaram como recomendações ou conclusões a importância da integralidade, de entender criança, mulher e família dentro do seu contexto social. Sugere-se o desenvolvimento de estudos exploratórios sobre a temática que possibilitem maior compreensão sobre esta prática e apontem estratégias para a educação em saúde neste contexto.

Descritores: Aleitamento materno; Recém-nascido prematuro; Recém-nascido.

ABSTRACT: Objective: to analyze the scientific production related to breast feeding in preterm births. Method: it is developed through an integrative review of the Scientific Electronic Library Online. It was included 12 articles from studies conducted in Brazil, published between 2000 and 2009. Results: the studies approached the importance of breast feeding in premature infants, the positive and negative influences for this practice and performance of professionals in this context. The highest incidence of publication was in 2004. On the authority revealed a greater amount of nurse's publication. Final considerations: the studies analyzed presented as recommendations or conclusions the importance of integrity, understanding the child, woman and family within their social context. It is suggested the development of exploratory studies on the subject to enable greater understanding of this practice and indicate strategies for health education in this context.

Descriptors: Breast feeding; Premature; Newborn.

RESUMEN: Objetivo: analizar la producción científica relacionada con la lactancia materna en prematuros. Método: se trata de una revisión integradora a través del Scientific Electronic Library Online. Se incluyeron 12 artículos publicados entre 2000 y 2009. Resultados: los estudios se centraron en la importancia de la lactancia materna en prematuros, las influencias positivas y negativas de esta práctica y desempeño de los profesionales en este contexto. La mayor incidencia de publicación ocurrió en el año 2004. Cuanto a los autores, muestra un mayor desarrollo de los enfermeros sobre los demás profesionales. Consideraciones finales: los estudios analizados presentaran como

\footnotetext{
${ }^{1}$ Enfermeira Obstetra. Mestranda em Enfermagem pela Universidade Federal do Rio Grande do Sul. E-mail: evelinefranco@yahoo.com.br

${ }^{2}$ Bacharel em Enfermagem. Faculdade Nossa Senhora de Fátima. E-mail: nandamuniz1@hotmail.com

${ }^{3}$ Enfermeira. Doutoranda em Ciências da Saúde. Instituto de Cardiologia do Rio Grande do Sul. E-mail: fhcecchetto@gmail.com
} 


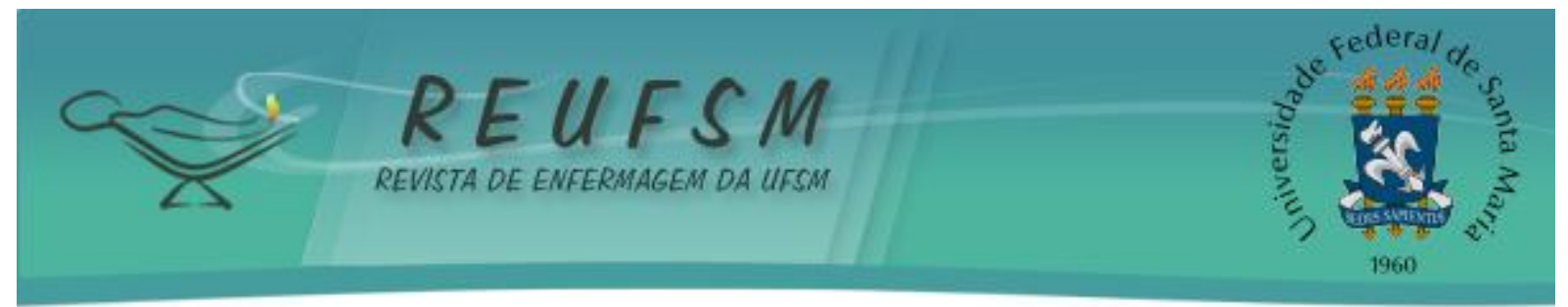

recomendaciones o conclusiones de la importancia de la integridad, la comprensión del niño, mujer y familia en su contexto social. Sugiere el desarrollo de estudios exploratorios sobre el tema para permitir una mayor comprensión de esta práctica e indicar las estrategias de educación para la salud en este contexto.

Descriptores: Lactancia materna; Prematuro; Recién nacido.

\section{INTRODUÇÃO}

0 aleitamento materno reduz significativamente o problema da morbimortalidade infantil ${ }^{1}$, fornecendo uma nutrição ideal ao lactente, favorecendo seu crescimento, a interação mãe-filho, possibilitando economia de recursos para as famílias e sociedade, logo, o aleitamento materno constitui-se em importante determinante de saúde pública..$^{2-3}$ Assim, recomenda-se a amamentação exclusiva até os seis meses e complementação até dois anos ou mais. ${ }^{4}$

Portanto, a amamentação deve ser considerada prioridade para o recém-nascido (RN), pois contém uma combinação única de proteínas, lipídios, carboidratos, minerais, vitaminas, enzimas e células vivas, assim como benefícios nutricionais, imunológicos, psicológicos e econômicos, todos os nutrientes necessários para o seu crescimento e desenvolvimento, especialmente para o prematuro, devido a sua maior vulnerabilidade. ${ }^{4-5}$

Compreende-se que o aleitamento materno em situação de prematuridade é um fator preocupante, que exige muita dedicação materna, apoio familiar e competência dos profissionais de saúde, uma vez que o próprio afastamento entre mãe e bebê, devido às condições críticas de saúde da criança, pode implicar na alimentação por leite artificial e, consequentemente, menor produção do leite materno. Nessas circunstâncias, convive-se com a insegurança, ansiedade e sofrimento materno, dificuldades específicas do RN e limites para os profissionais.

Portanto, na prática assistencial intra-hospitalar é importante estabelecer a amamentação e orientar adequadamente mãe e família para que no domicílio possam manter a amamentação. ${ }^{1}$ Face ao exposto, o objetivo deste estudo foi analisar as produções científicas que abordam o aleitamento materno na prematuridade.

\section{MÉTODO}

Trata-se de uma revisão integrativa. A revisão integrativa da literatura é um método de pesquisa que permite a incorporação das evidências na prática clínica com a finalidade de reunir e sintetizar resultados de pesquisas sobre determinado tema ou questão, de maneira sistemática e ordenada. ${ }^{6-7}$ Para elaboração deste estudo, pautados na metodologia de elaboração de revisões integrativas ${ }^{6-8}$, percorreram-se as etapas: formulação da questão norteadora; coleta de dados; avaliação; análise e interpretação dos dados; apresentação dos resultados. ${ }^{6}$ Para nortear esta pesquisa formulou-se a questão: como as produções científicas tem abordado o aleitamento materno na prematuridade?

Definiu-se como fonte de busca o Scientific Eletronic Library Online (SciELO), que é uma considerada referência na produção na área da saúde. Nesta, utilizaram-se os descritores recém-nascido prematuro e aleitamento materno.

Inicialmente, para seleção dos estudos desta revisão integrativa, foram definidos os critérios de inclusão: somente artigos, publicados em idioma português, oriundos de estudos realizados no Brasil, com ano de publicação entre 2000 e 2009, convergentes com a proposta do estudo de aleitamento materno na prematuridade. Foram excluídos os estudos internacionais, artigos com ano de publicação inferior a 2000 , sem resumo e as duplicidades. A busca pelas produções foi conduzida no período entre abril e junho de 


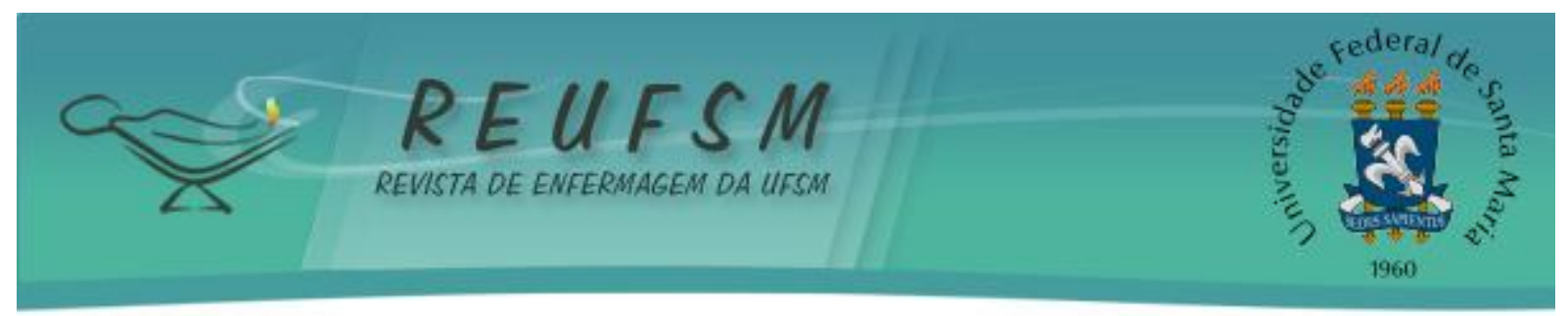

2010. Foi estabelecido o recorte temporal, pois no ano de 2000 o Ministério de Saúde instituiu o Programa de Humanização do Pré-Natal e Nascimento (PHPN), após, outros programas e normas foram lançados para complementar o PHPN e a assistência ao RN. ${ }^{9}$

Para análise e posterior síntese dos artigos, as autoras construíram um quadro sinóptico, que contemplou os aspectos considerados pertinentes: nome do artigo, objetivos, resultados e recomendações/conclusões. Para apresentação dos resultados esse quadro foi dividido em duas tabelas, para facilitar a leitura e discussão dos achados científicos. Foram identificados 446 estudos na base de dados SciELO. Após uma análise minuciosa, observou-se que 12 artigos atendiam aos critérios estabelecidos. Estes, então, constituíram a amostra desta revisão integrativa.

Os dados utilizados neste estudo foram devidamente referenciados, respeitando e identificando seus autores e demais fontes de pesquisa, observando o rigor ético quanto à propriedade intelectual dos textos científicos que foram pesquisados, no que diz respeito ao uso do conteúdo e de citação das partes das obras consultadas. ${ }^{10}$ A fim de manter a avaliação cega, os artigos foram codificados (A01, A02, ..., A12), somente após análise foram identificados os autores.

\section{RESULTADOS E DISCUSSÃO}

Apresenta-se nos Quadros 01 e 02 a síntese dos estudos desta revisão integrativa.

\begin{tabular}{|c|l|c|c|}
\hline CÓDIGO & \multicolumn{1}{|c|}{ AUTORES } & \multicolumn{1}{|c|}{ PERIÓDICOS } & $\begin{array}{c}\text { ANO DE } \\
\text { PUBLICAÇÃO }\end{array}$ \\
\hline A01 & $\begin{array}{l}\text { Javorski M, Caetano LC, Vasconcelos } \\
\text { MGL, Leite AM, Scochi CGS. }\end{array}$ & Rev Latino-am Enfermagem & 2004 \\
\hline A02 & Nascimento MBR, Issler H. & J Pediat & 2004 \\
\hline A03 & Serra SOA, Scochi CGS. & Rev Latino-am Enfermagem & 2004 \\
\hline A04 & Venâncio SI, Almeida H. & \multicolumn{1}{|c|}{ Jediat } & 2004 \\
\hline A05 & $\begin{array}{l}\text { Fonseca LMM, Scochi CGS, Rocha SMM, } \\
\text { Leite AM. }\end{array}$ & Rev Latino-am Enfermagem & 2004 \\
\hline A06 & Giugliani ERJ. & J Pediat & 2000 \\
\hline A07 & Almeida JAG, Novak FR. & J Pediat & 2004 \\
\hline A08 & $\begin{array}{l}\text { Pedras CTPA, Pinto EALC, Mezzacappa } \\
\text { MA. }\end{array}$ & Rev Bras Saúde Mater Infant & 2008 \\
\hline A09 & Braga DF, Machado MMT, Bosi MLM. & Rev Nutr & 2008 \\
\hline A10 & $\begin{array}{l}\text { Silva ACMG, Alencar KPC, Rodrigues } \\
\text { LCB, Perillo VCA. }\end{array}$ & Rev Soc Bras Fonoaudiol & 2009 \\
\hline A11 & $\begin{array}{l}\text { Maia DB, Chaves EMC, Caetano JÁ, } \\
\text { Campos ACS. }\end{array}$ & Rev Enferm Atual & 2006 \\
\hline A12 & Regiani C, Juliani CMCM, Manoel CM. & Rev Enferm atual & 2004 \\
\hline
\end{tabular}

Quadro 01 - Descrição dos estudos incluídos na revisão integrativa, segundo autores, periódicos e ano de publicação.

Observa-se maior incidência de publicações (sete artigos) durante o ano de 2004. Tal fato pode ser justificado pela Portaria $n^{\circ} 693$ de 2000, que apresenta a Norma de Atenção Humanizada do Recém-Nascido de Baixo Peso (Método Canguru), e pela influência da $54^{a}$ Assembléia Mundial de Saúde, que ocorreu em Genebra no ano de 2001, onde a Organização Mundial de Saúde passou a preconizar o aleitamento materno exclusivo até o sexto mês de vida. ${ }^{11}$ No mesmo ano, no Brasil, o Ministério da Saúde apresentou os resultados da pesquisa de prevalência do aleitamento materno nas capitais e no Distrito Federal e, posteriormente, em 2002, lançou o guia alimentar para crianças menores de 


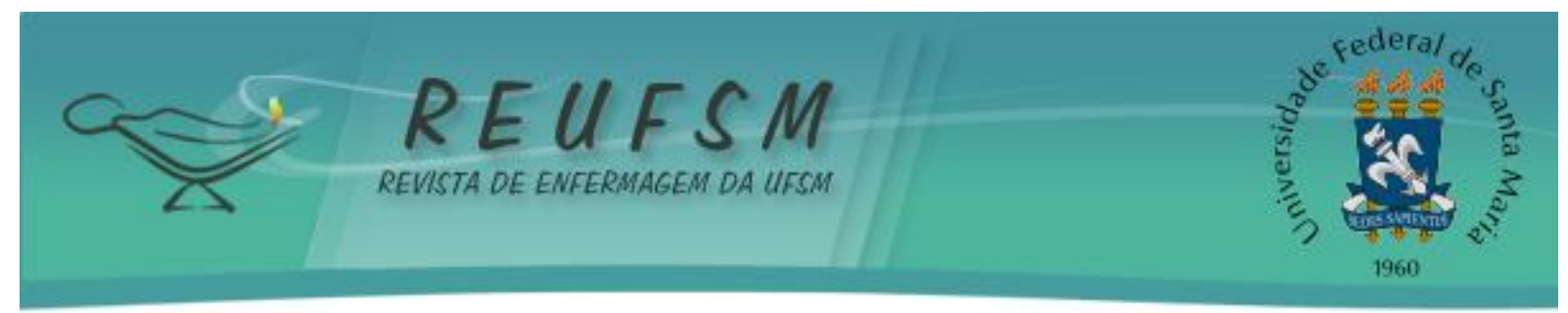

dois anos. ${ }^{11-13}$ Tais evidências podem ter instigado pesquisadores a conhecer mais a temática do aleitamento materno na prematuridade.

Quanto aos periódicos, constata-se que a maioria são destinados à área de enfermagem e pediatria. Os artigos analisados possuem como autor principal cinco enfermeiros, quatro médicos, dois fonoaudiologistas e uma assistente social. Percebe-se que a enfermagem se apresenta mais sensibilizada e disposta em investigar o aleitamento materno na situação de prematuridade. Este fato pode estar relacionado ao atendimento direto, intenso e constante que enfermeiros proporcionam à mãe e família do prematuro. ${ }^{14}$ Porém, isto revela que as equipes de saúde não atuam de maneira integrada, embora as políticas de saúde corroborem para que assim seja.

Os artigos analisados buscaram investigar aspectos sociais do aleitamento materno na prematuridade, a vivência materna neste contexto, a prevalência do aleitamento materno em prematuros, o aleitamento do prematuro por meio do uso do copo, a descrição do Método Canguru, entre outros, conforme é descrito no Quadro 02.

\begin{tabular}{|c|c|c|}
\hline CÓDIGO & TÍTULO & OBJETIVO \\
\hline A01 & $\begin{array}{l}\text { As representações sociais } \\
\text { do aleitamento materno } \\
\text { para mães de prematuros } \\
\text { em unidade de cuidado } \\
\text { canguru }\end{array}$ & $\begin{array}{l}\text { (1) Identificar as representações sociais sobre } \\
\text { aleitamento materno de pré-termo, em unidade de } \\
\text { cuidado canguru, sob a ótica das mães que estão } \\
\text { amamentando; } \\
\text { (2) Descrever os conflitos e contradições que eles } \\
\text { vivenciam nesse contexto institucional. }\end{array}$ \\
\hline $\mathrm{AO2}$ & $\begin{array}{l}\text { Aleitamento materno em } \\
\text { prematuros: } \quad \text { manejo } \\
\text { clínico hospitalar }\end{array}$ & $\begin{array}{l}\text { Abordar a importância do aleitamento materno e sua } \\
\text { promoção no manejo clínico-hospitalar de recém- } \\
\text { nascidos (RNs) pré-termo. }\end{array}$ \\
\hline $\mathrm{A} 03$ & $\begin{array}{l}\text { Dificuldades maternas no } \\
\text { processo de aleitamento } \\
\text { materno de prematuros } \\
\text { em uma UTI Neonatal }\end{array}$ & $\begin{array}{l}\text { Descrever a assistência e as dificuldades maternas no } \\
\text { processo do aleitamento materno de prematuros } \\
\text { assistidos em uma unidade de terapia intensiva } \\
\text { neonatal. }\end{array}$ \\
\hline A04 & $\begin{array}{lcc}\text { Método mãe } & \text { canguru: } \\
\text { aplicação } & \text { no Brasil, } \\
\text { evidências científicas } & \text { e } \\
\text { impacto } & \text { sobre } & \text { o } \\
\text { aleitamento materno } & \end{array}$ & $\begin{array}{l}\text { (1) Descrever o histórico do Método Mãe Canguru; } \\
\text { (2) Apresentar evidências científicas sobre os benefícios } \\
\text { dessa prática para os bebês de baixo peso no tocante a } \\
\text { morbimortalidade, desenvolvimento psicoafetivo, } \\
\text { neurossensorial e amamentação. }\end{array}$ \\
\hline A05 & $\begin{array}{l}\text { Cartilha educativa para } \\
\text { orientação materna sobre } \\
\text { os cuidados com o bebê } \\
\text { prematuro }\end{array}$ & $\begin{array}{l}\text { Descrever o desenvolvimento de material didático- } \\
\text { instrucional, dirigido ao treinamento materno para } \\
\text { preparar a alta hospitalar do bebê prematuro. }\end{array}$ \\
\hline A06 & $\begin{array}{l}\text { O aleitamento materno na } \\
\text { prática clínica }\end{array}$ & $\begin{array}{l}\text { Apresentar uma revisão atualizada sobre aspectos } \\
\text { práticos na promoção e no manejo do aleitamento } \\
\text { materno. }\end{array}$ \\
\hline A07 & $\begin{array}{l}\text { Amamentação: um híbrido } \\
\text { natureza-cultura }\end{array}$ & $\begin{array}{l}\text { Contribuir para a construção de uma nova síntese } \\
\text { teórica das inter-relações entre o biológico e o social no } \\
\text { cenário da amamentação, categorizando-a com um } \\
\text { híbrido natureza-cultura. }\end{array}$ \\
\hline A08 & $\begin{array}{l}\text { Uso do copo e da } \\
\text { mamadeira e o o } \\
\text { aleitamento materno em } \\
\text { RNs prematuros e a termo: } \\
\text { uma revisão sistemática }\end{array}$ & $\begin{array}{l}\text { Revisar ensaios clínicos randomizados que avaliaram a } \\
\text { prevalência e/ou duração do aleitamento materno na } \\
\text { alta hospitalar e/ou durante o primeiro ano de vida, em } \\
\text { RNs a termo ou prematuros. }\end{array}$ \\
\hline
\end{tabular}




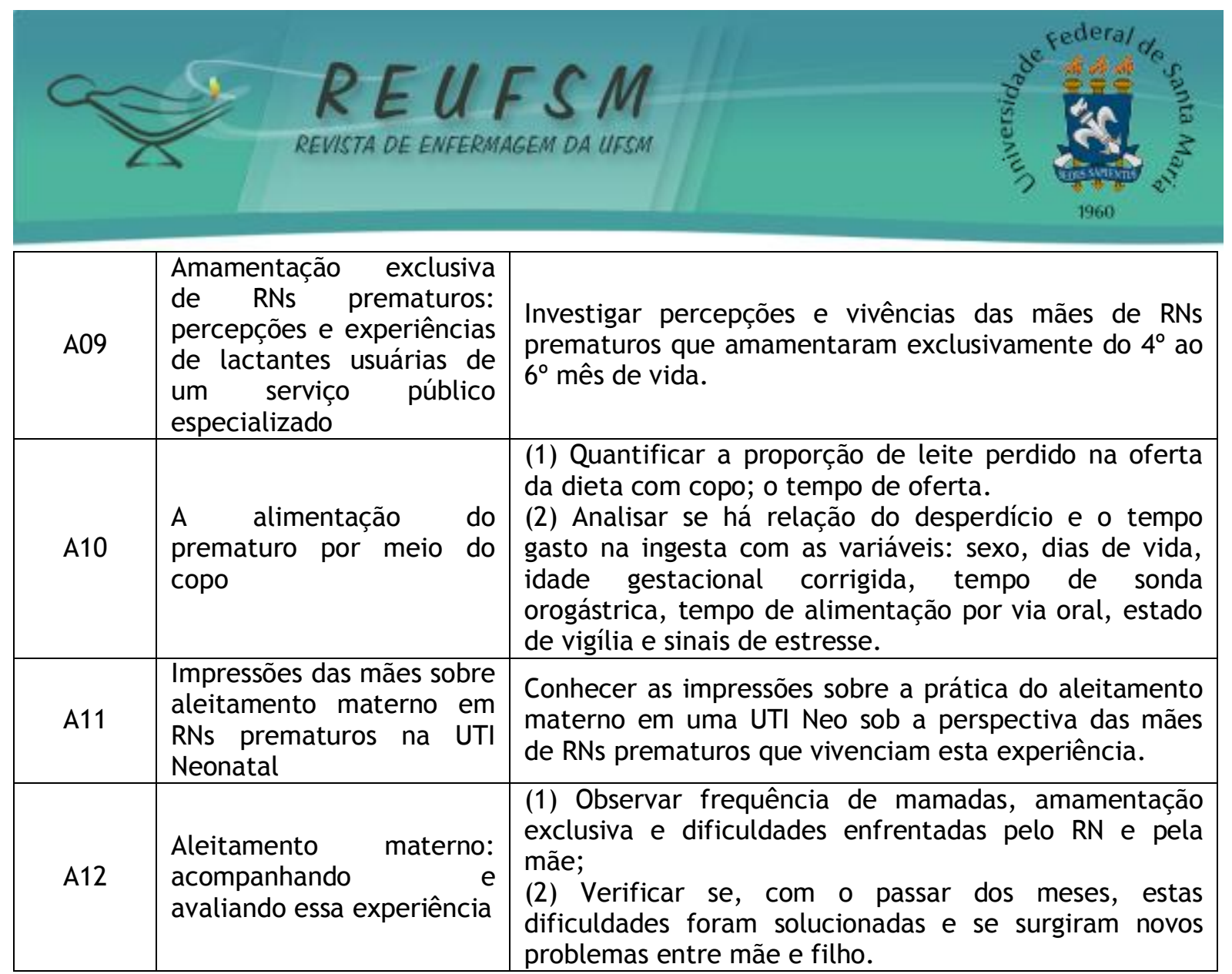

Quadro 02 - Apresentação da síntese de artigos incluídos na revisão

A partir dos objetivos propostos nos estudos, é possível identificar que as produções visam estudar as dificuldades que as mães enfrentam para iniciar o aleitamento materno e mantê-lo na situação de prematuridade.

Os estudos A01, A07 e A11 apresentam a necessidade de assistência integral à mulher mãe e ao RN prematuro, incluindo sua família e compreendendo suas vivências, culturas e condições sociais. ${ }^{15-17} \mathrm{O}$ estudo $\mathrm{A} 12$ revela o aleitamento materno como prática importante e valorizada pelas mães que buscam atender as necessidades do RN. ${ }^{18}$

Entende-se que o desconforto materno, a vulnerabilidade e condições clínicas dos bebês são alguns dos fatores atribuídos às dificuldades maternas, assim considera-se necessário o acolhimento das mães como uma maneira de favorecer o luto em relação à prematuridade, segurança frente à hospitalização e maturação das funções materna e paterna. ${ }^{19}$

O estudo A03 aponta que dificuldades maternas no processo do aleitamento materno decorrem da falta de infraestrutura para amamentar e ordenhar o leite materno, bem como dos recursos que dispõem para transporte e cuidado dos outros filhos. ${ }^{20}$ Por outro lado, sabe-se que as práticas de apoio, observação das mamadas, aprendizado da pega adequada e incentivo ao aleitamento materno dependem de recursos humanos, ou seja, os profissionais de saúde podem usar estratégias dentro dos limites e possibilidades que encontram na prática diária assistencial. ${ }^{21}$

Entende-se que a amamentação também é influenciada pelo ambiente, dessa forma, considera-se importante trabalhar nas instituições de saúde que atendem puérperas e RNs, especificamente nas unidades de alojamento conjunto e neonatal, os dispositivos da humanização em saúde, dando especial atenção a ambiência. ${ }^{22}$

Paralelamente, todos os estudos discutem ou deixam subentendida a importância da educação. Os profissionais de saúde devem incentivar e dar suporte para o sucesso do aleitamento materno, contudo, isto somente é possível a partir da educação continuada e educação em saúde. ${ }^{23-24}$ Entende-se que somente informar não é a solução para estabelecer e manter a amamentação. É necessário que os profissionais estejam preparados para 


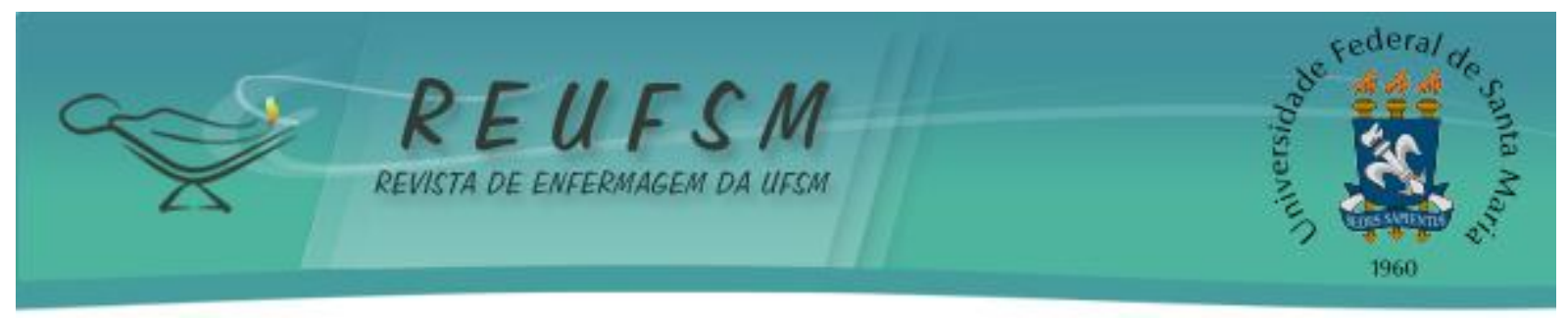

trabalhar com a mulher, provedora do alimento do seu filho, através da educação em saúde, no seu modelo radical, abordagem que propõe atender as complexidades da nova saúde pública e a trabalhar uma perspectiva moderna de educação, centrada na consciência crítica das pessoas. ${ }^{25}$

0 estudo A04 recomenda a realização de estudos sobre a efetividade, aplicabilidade e aceitabilidade do Método Mãe Canguru na assistência de enfermagem. ${ }^{26}$ Ainda, o A08 e A10 recomendam mais investigações sobre o aleitamento materno do prematuro por meio do uso do copo. ${ }^{2,27}$ Acredita-se que a abordagem destes dois temas pode possibilitar maior compreensão sobre a ocorrência do aleitamento na prematuridade e o enfrentamento do mesmo pelas mães, pelos RNs e pelos profissionais de saúde.

\section{CONSIDERAÇÕES FINAIS}

Identificou-se que a maioria dos estudos foram publicados durante o ano de 2004, podendo ter relação com o período em que as políticas de saúde à criança e ao recémnascido foram reforçadas.

De modo geral, os estudos analisados apresentaram como recomendações ou conclusões a importância da integralidade, de entender a criança, mulher e família dentro do seu contexto social. Constatou-se, também, questões que envolvem a educação continuada, a educação em saúde, a atenção integral aos RNs prematuros, suas mães e famílias, uma vez que estes fatores influenciam no estabelecimento e manutenção da amamentação nessas condições.

Frente ao exposto, considera-se relevante a investigação do aleitamento materno em RNs prematuros, sugere-se o desenvolvimento de estudos exploratórios sobre a temática que possibilitem maior compreensão sobre esta prática e apontem estratégias para a educação em saúde neste contexto.

\section{REFERÊNCIAS}

1. Scochi CGS, Kokuday MLP, Riul MJS, Rossanez LSS, Fonseca LMM, Leite AM. Incentivando o vínculo mãe-filho em situação de prematuridade: as intervenções de enfermagem no Hospital das Clínicas de Ribeirão Preto. Rev latinoam enferm. 2003;11(4):539-43.

2. Pedras CTPA, Pinto EALC, Mezzacappa MA. Uso do copo e da mamadeira e o aleitamento materno em recém-nascidos prematuros e a termo: uma revisão sistemática. Rev bras saúde matern infant. 2008;8(2):163-9.

3. UNICEF. Situação mundial da infância - 2009. Brasília, DF: Escritório da Representação do UNICEF no Brasil; 2009.

4. Brasil. Ministério da Saúde. Saúde da criança: nutrição infantil: aleitamento materno e alimentação complementar. Brasília, DF; 2009.

5. Nascimento MBR, Issler $\mathrm{H}$. Aleitamento materno em prematuros: manejo clínico hospitalar. J pediatr (Rio J). 2004;80(5).

6. Mendes KDS, Silveira RCCP, Galvão CM. Revisão integrativa: método de pesquisa para a incorporação de evidências na saúde e na enfermagem. Texto \& contexto enferm. 2008;17(4):758-64.

7. Whittemore R, Knafl K. The integrative review: updated methodology. J Adv Nurs. 2005;52(5):546-53. 


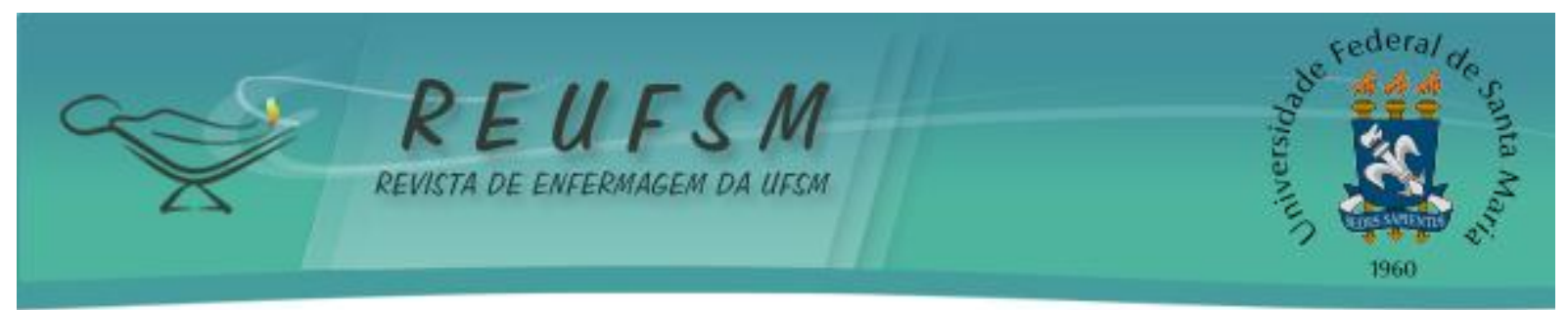

8. Souza MT, Silva MD, Carvalho R. Revisão integrativa: o que é e como fazer. Einstein. 2010;8(1):102-6.

9. Brasil. Ministério da Saúde. Atenção humanizada ao recém-nascido de baixo peso: Método Canguru. 2a ed. Brasília, DF; 2011.

10. Gil AC. Como elaborar projetos de pesquisa. $4^{\text {a }}$ ed. São Paulo: Atlas; 2002.

11. Brasil. Ministério da Saúde. Portaria $n^{\circ} 693$, de 5 de julho de 2000. Dispõe sobre norma de orientação para implantação do Método Canguru. Brasília, DF; 2000.

12. Brasil. Ministério da Saúde. Guia alimentar para crianças menores de dois anos. Brasília, DF; 2002.

13. Brasil. Ministério da Saúde. Pesquisa de prevalência do aleitamento materno nas capitais e no Distrito Federal. Brasília, DF; 2001.

14. Almeida NAM, Fernandes AG, Araújo CG. Aleitamento materno: uma abordagem sobre o papel do enfermeiro no pós-parto. Rev eletrônica enf. 2004;6(3):358-67.

15. Javorski M, Caetano LC, Vasconcelos MGLd, Leite AM, Scochi CGS. As representações sociais do aleitamento materno para mães de prematuros em unidade de cuidado canguru. Rev latinoam enferm. 2004;12(6):890-8.

16. Almeida JAG, Novak FR. Amamentação: um híbrido natureza-cultura. J pediatr. 2004;80(5 Supl):S119-S25.

17. Maia DB, Chaves EMC, Caetano JA, Campos ACS. Impressões das mães sobre aleitamento materno em RNs prematuros na UTI neonatal. Enferm atual. 2006;6(34):17-21.

18. Regiani C, Monti CMC, Manoel CM. Aleitamento materno: acompanhando e avaliando essa experiência. Enferm atual. 2004;4(23):29-33.

19. Bragheto ACM, Jacob AV. Suporte psicológico às mães de prematuros em uma UTI neonatal: relato de experiência. Saúde e transformação soc. 2011;1:174-8.

20. Serra SOA, Scochi CGS. Dificuldades maternas no processo de aleitamento materno de prematuros em uma UTI neonatal. Rev latinoam enferm. 2004;12(4):597-605.

21. Joventino ES, Dodt RCM, Araujo TL, Cardoso MVLML, Silva VM, Ximenes LB. Tecnologias de enfermagem para promoção do aleitamento materno: revisão integrativa da literatura. Rev gaúc enfer. 2011;32(1):176-84.

22. Heckert ALC, Passos E, Barros MEB. Um seminário dispositivo: a humanização do Sistema Único de Saúde (SUS) em debate. Interface comun saúde educ. 2009;13:493-502.

23. Braga DF, Machado MMT, Bosi MLM. Amamentação exclusiva de recém-nascidos prematuros: percepções e experiências de lactantes usuárias de um serviço público especializado. Rev nutr. 2008;21(3):293-302.

24. Fonseca LMM, Scochi CGS, Rocha SMM, Leite AM. Cartilha educativa para orientação materna sobre os cuidados com o bebê prematuro. Rev latinoam enferm. 2004;12(1):65-75.

25. Oliveira DL. A 'nova' saúde pública e a promoção da saúde via educação: entre a tradição e a inovação. Rev latinoam enferm. 2005;13(3):423-31.

26. Venancio SI, Almeida H. Método Mãe-Canguru: aplicação no Brasil, evidências científicas e impacto sobre o aleitamento materno. J pediatr (Rio J). 2004;80(5):S173-S80. 


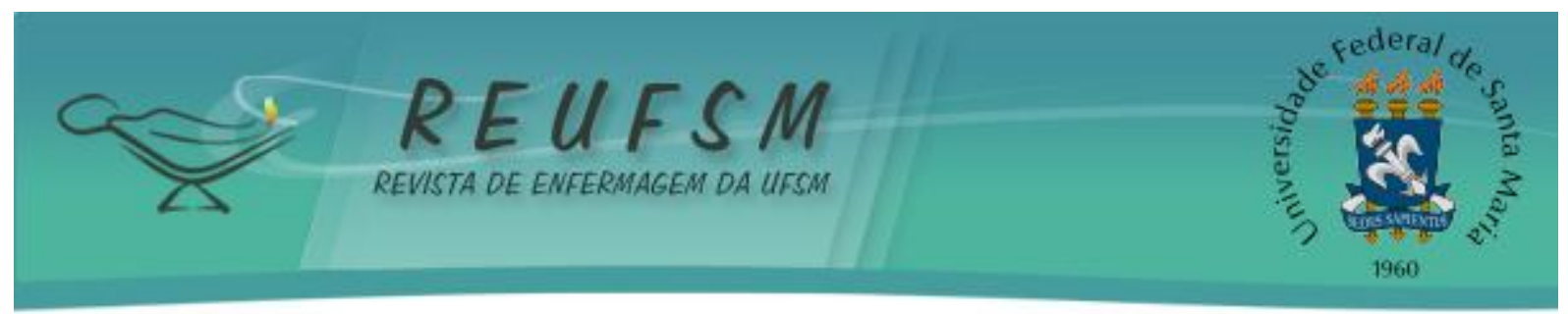

27. Silva ACMG, Alencar KPC, Rodrigues LCB, Perillo VCA. A alimentação do prematuro por meio do copo. Rev Soc Bras Fonoaudiol. 2009;14(3):387-93.

Data de recebimento: $30 / 06 / 2011$

Data de aceite: $12 / 12 / 2011$

Contato com autor responsável: Eveline Franco da Silva

Endereço: Rua Alexandre Fleming, 454 - Caxias do Sul, RS, Brasil.

CEP: 95041-520

E-mail: evelinefranco@yahoo.com.br 